\title{
RISK MANAGEMENT IN MICRO PAYMENT SYSTEM IN EMERGING ECONOMY: AN EMPIRICAL STUDY FROM GHANA
}

\author{
Owusu Ackah $^{1 *}$, Emmanuel Oteng ${ }^{2}$, Antwi John Osei ${ }^{3}$, Doris Agyeiwaa ${ }^{4}$ \\ ${ }^{1}$ School of Management and Economics University of Electronic Science and Technology of China \\ ackah_owusu@yahoo.com \\ ${ }^{2}$ School of Finance and Economics Southwest University of Finance and Economics \\ emmoteng@hotmail.com \\ ${ }^{3}$ School of Management and Economics University of Electronic Science and Technology of China \\ johnoseiantwi@ymail.com \\ ${ }^{4}$ School Of Management and Economics University of Electronic Science and Technology of China \\ doagsa@gmail.com
}

\section{*Corresponding Author: -}

Email: ackah_owusu@yahoo.com

\begin{abstract}
: -
This study examined the relationship between risk communication and review process and the entire risk management process in micro payment system. An empirical study was conducted into this phenomenon. Questionnaire was used to collect data from key informants within the micro payment industries. In all a total of 120 respondents was used. Furthermore, Pearson correlation and Linear regression analysis was conducted to test the hypotheses stated for this study. According to the statistical finding of this study is proved that information dissemination between providers and clients contributed significantly to risk mitigation and reduction. Also risk communication process coupled with a review process enabled firms to deal with ineffective strategies and practices.
\end{abstract}

Keyword: - Risk Communication, firm, empirical study, micro payment 


\section{INTRODUCTION}

The rapid growth in the development of mobile technology throughout the world is a phenomenon that is especially know among people in emerging economies and markets, due to the prepaid nature of it. Because of this growth most people within the population now have access to financial service that is introduce in the form of mobile- money system. According to (Beshouri et al, 2010), despite there are over one hundred and twenty (120) mobile money project in seventy (70) emerging market, the use of these mobile payments has been accepted and practice in a few countries.

Over the last decade the mobile phone has evolve from its traditional way of sending and receiving both phone calls and short "text" messages. It is now used as a tool for electronic transaction. The mobile phone compared to other channels or tools used as a medium for electronic transactions the capital investment and the needed human resources and the technological infrastructure is relatively cheap. Several processes has been put in place to create the necessary platform for electronic payment, which can be done by simply sending short "text" messages or through phone calls. This kind of payment is referred to as the Mobile Payment (m-payment) (Vassiliou, 2004). In this kind of payment follows a simple channel such that the 'issuer' identify himself or herself to the 'receiver' by placing a phone call to the 'receiver' or the 'receiver', the receiver send the information to the customers service provide (through a mobile network), the service provider will then ask for the authenticity of the transaction from the issuer, after been authenticated the transaction is recorded. This model has been operational across the part of the world, for example Paybox (Austria, Germany, Spain, Sweden and the United Kingdom), Mint (Sweden) and e-pay (Finland) (Vassiliou, 2004). Ghana now enjoys its own share of this model of payment as back as 2009 with the lunching of "txtnpay" by Afri Xpress, now there are other competitors are also enrolled unto this platform mostly by the telecommunication companies, other product they have introduces includes; MTN mobile money, Tigocash and Airtel money all own by telecommunication companies. The increase of the number of users who now subscribe to mobile phone usage has contributed to the success of this payment model, for example in Ghana the number of mobile phone users has increase to $80.5 \%$ of the overall population per information released by the Ministry of Communication and published by the Ghana News Agency (GNA). In fact, the use of mobile technology as a payment and banking medium or channel over the year has the potential to address two major issues in emerging economies, first it provide it provide financial inclusion for the section of population that do not subscribe to the traditional form of banking service. Whiles on the other side of the coin, it presents a whole new opportunity for financial and banking institutions to develop and deliver a wide range of diversified banking services to the a large section of the poor population who live in remote areas in the country at a relatively lower cost as compare to cost involved in traditional banking (Eduardo et al, 2011).

Despite the numerous opportunities and benefits that mobile payments have presented to both firms and individual there still exist a number of hurdles that affected the successful execution of this process. Mobile payment providers as business entities operating in a dynamic business environment are faced with a number of uncertainties (Marlyin et al, 2002). Therefore for firms to create value whiles satisfying customers it is essential for firms to be able to eliminate risk associated with this process. Therefore risk management should be considered a strategy activity within the organization. This would enable firms to mitigate risk associated with its online product (Anderson, 2006). Although firms take steps to mitigate these uncertainties associated with micro payment a lot has being focus on the technical and quantitative aspect of it (Reith, 2004: Boholm, 2003). Firms mostly ignore the human and socio-economic aspects. Although firms place most emphasizes on the technological risk management this leads to firms ignoring the end users. The end users turns not to be aware of the risk and uncertainties associated with the adaptation of such a product. Therefore making risk communication an essential process that firms needs to undertake. Firms have a mandate to communicate anticipated risk and uncertainties to potential user such and this would increase customer satisfaction. Furthermore it would enable firms to create the expected value (Bradbury, 1994; Haag, 2009; Kerzner, 2001; Neitlich, 2009).

This study seeks to examine the relationship between risk communication and review can manage risk effectively. When firms communicate the expected uncertainties it has a positive influence on the entire risk management process. Since communication turns to be a two-way interaction it enable firms to gain information relating to risks that are prioritized by customers. Firms can review and implement effective strategies to mitigate unmitigated risks and uncertainties. This would provide customer satisfaction since firms would provide the expected value and quality. The study place emphasizes on micro online payment providers in Ghana. This has being motivated by the increase in micro payment through mobile phone adaptation in recent times. The paper is arranges as follows, section 2 focus on the theoretical framework and hypothesis for this study, section 3 discusses the methodology adopted for this study, section 4 presents the statistical findings and finally the last section focus on the conclusion of this study.

\section{Theoretical Background and Hypothesis}

Risk communication is an interactive flow procedure where information concerning risk is exchanged or shared between risk assessors, risk managers and other related clients and parties (WHO, 1998). In 1989 the national Research council identified risk communication as an essential tool in risk management. This tool serves as a link between the assessment of risk, decision - makers and other parties such as clients involved. The prediction-oriented style and management - oriented style of risk communication has been put forward in a study conducted by (Heilbrun 1997) makes it an essential or relevant tool in the management of risk. Risk communication should be a two-way, interactive and a long-term process where each party should be engaged in the process (Rowan, 1994), and it this process help avoid possible litigation (Marilyn et al, 2002). Providing information about risk and opportunities will help improved mitigation policies and strategies. 
The hypothesis was put forward;

Hla: The communication of risk during the whole payment process serves as a positive impact to risk management.

Risk mitigation policies and measures should be monitored and evaluated for its effectiveness after it has been developed and implemented. When policies are being implemented and in operational stage, its progress should be monitored at every stage to ascertain whether the objective establish is achieved. The data from the monitoring stage is used to evaluate the risk mitigation policies and strategies for any form of deviation. An effective risk-monitoring plan should be developed to track any form of deviation from the plan or standard. To make the stage effective it should be an ongoing process and not an event (Marilyn et al, 2002). In doing this we get to know whether the controls in place are performing as expected, that is effective or not effective. During the monitoring stage the control measure can be reviewed to produce a more effective way of controlling the risk and this makes this stage a more essential tool in risk management. Risk monitoring and review involves the tracking of policies, inputs and output and evaluate its impact (rdec.gov.tw, 2006). When a risk mitigation policy does not meet its objectives, there is the need to revise these policies and strategies to suit the situation. This process should be done side by side with the monitoring process. Ongoing review is essential to ensure that circumstance does not change the risk priorities and the current mitigation policies are still relevant (Thomas et al, 1997). With this the following hypothesis was put forward;

$H 1 b$ : The review of risk control measure of the whole payment process serves as a positive impact to risk management.

\section{Methodology}

\subsection{Research Method and Data Analysis}

The study adopted both qualitative and quantitative methods to arrive at its findings. These methods were adopted in order to conduct an empirical study into how risk communication between providers and customers enables firms to mitigate risk. Data collection and gathering was done through field survey and interviews. Furthermore, SPSS statistical software was adapted to test the hypotheses stated for the purpose of this study.

Furthermore, in other the test our hypothesis there is the need to define our variables. In our study our dependent variable is Risk Management (RM) and the following independent variables, Effectiveness of Risk Communication process (ERC), Dissemination of firm's procedure on risk mitigation to employees (ADFR), Information sharing between providers and customers (INFSHA), Flexibility of customer complaint process (CFED), Effectiveness of review process (ERP).

The SPSS version 20 Statistical package was used to conduct both Pearson correlation and linear regression analysis on the data acquired to test the influence that independent variables had on the dependent variable. This would enable the researcher to examine to what extent each variable has on the attainment of success online transactions.

\subsection{Population and Sampling Method}

To enable relevant statistical inferences from the data acquired there is the critical step to identity the right sample for a particular study (Polit et al, 2001). Further the ability to identify and collect data from key informants within the identified sample is critical to the outcome of this study (Campbell, 1995). In this study the key informant identified includes employees of mobile payment providers. This is essential because it enable us to gather firsthand information as to how firms handle the risk communication and review process.

After identifying the sample for this study a random sampling method was adopted to collect data (Mark et al, 2009; Creswell, 2007; Barnet, 1991). Initial contact was made through emails. Firms were sent electronic mails to explain the objective and significances of this study and also to solicit for their permission to use their employees as respondents for our survey.

\subsection{Data Collection}

Data was mainly gathered through field survey and the administering of questionnaires to employees of micro payment providers in Ghana. This approach was adopted because the study seeks to acquire data from real world actors or individuals (Campbell, 1995; Galaskiwicz, 1985). The survey was carried out within a period of three months. This is due to the collection of data from multiple location or firms. And this requires much time and resources. Respondents turned out to be located in different geographical location and workstations making it impossible to collect data at a rapid pace. During this process respondents were handled out questionnaires to fill examining their perception of the risk communication and review process on a 7-liket scale.

After the three-month period a total of One hundred and fifty (150) respondents have been surveyed for the study. The respondents were sorted out to eliminate questionnaire that was not filled out or filled half way. After this process the total number of accurately filled questionnaires amounted to 120 filled questionnaires.

\subsection{Statistical Analysis}

The table below reports the descriptive statistics and Pearson correlation of variable used to test our data on risk communication and review process. 
Table 1: Descriptive Statistics and Pearson Correlation Output

\begin{tabular}{|c|c|c|c|c|c|c|c|}
\hline VARIABLES & MEAN & SD & 2 & 3 & 4 & 5 & 6 \\
\hline 1. RM & 4.23 & .902 & .500 & $.623^{*}$ & $.786^{* *}$ & $.524^{*}$ & $.896^{* *}$ \\
\hline 2.ERC & 5.96 & .807 & & $.479^{* *}$ & $.454^{* *}$ & $.678^{*}$ & $.415^{* *}$ \\
\hline 3.ADFR & 3.01 & 1.467 & & & .537 & $716^{* *}$ & $.574^{* *}$ \\
\hline 4. INFSHA & 5.35 & 1.053 & & & & $.600^{*}$ & .543 \\
\hline 5. CFED & 5.53 & 1.053 & & & & & $.644^{* *}$ \\
\hline 6. ERP & 4.25 & .787 & & & & & \\
\hline
\end{tabular}

** correlation is significant at 0.01 level(2-tailed).

* Correlation is significant at 0.05 level(2-tailed).

From the above it shows that all independent variables tested had a positive correlation with the dependent variable, with the effectiveness of the risk policy review having the highest co-efficient value of 0.896 at $p<0.01$ ( 2 -tailed). The other independent variable such as information sharing between providers and clients and flexibility of client complaint process at 0.786 at $\mathrm{p}<0.01$ (2-tailed) and 0.526 at $\mathrm{p}<0.05$ (2-tailed) respectively. Inferences from the statistical figures above proves that when employee follow policies outline by the firm in relation to the discharge of their duties at each stage of the transaction stage it will go a long way to help the risk management process. Furthermore, if the firm to be able to mitigate risk and improve the value of its service there is the need to make available adequate and reliable information concerning risk associated with the use of their payment solutions. Risk communication should also include anticipated risk. If employees follow procedure to the button, it minimizes the level of risk. Also, when clients are aware of the risk they face and also the measure that are employed by the firm to mitigate it, they turn to have faith and trust in this payment system, and it help boost the firm's reputation and brand. In our study we found out that the firm took a step in communicated risk to its clients and partners. Our findings showed that the firm did shared information with it users.

Furthermore, regression analysis was conducted to the model that had an influence on the relationship between the dependent variable and the independent variable. We adopted the linear regression equation used to test the other variables above. The equation shown below,

$$
\mathrm{Y}=\beta 0+\beta 1 \mathrm{X} 1+\beta 2 \mathrm{X} 2+\beta 3 \mathrm{X} 3+\ldots \ldots . \mathrm{BnXn}
$$

According to our model below it can be inferred that the 'model 5' had the highest R-square value of 0.867 , which indicates that this model explains that the model can explain $86 \%$ of the dependent variable. And this proves that all the independent variables tested for this study to a greater extent had an influence on the risk management process. And this supports out hypothesis $1 \mathrm{a}$ and $1 \mathrm{~b}$ stated above.

The table 2 below shows the regression analysis of the risk communication variables.

Table 2: Regression Anaysis

\begin{tabular}{|c|c|c|c|c|c|}
\hline & R-square & \multicolumn{2}{|c|}{$\begin{array}{c}\text { Unstandardized } \\
\text { coefficients. }\end{array}$} & $\begin{array}{c}\text { Standardized } \\
\text { coefficient }\end{array}$ & \multirow{2}{*}{ t-value } \\
\cline { 2 - 5 } & Beta & $\begin{array}{c}\text { Standard } \\
\text { Error }\end{array}$ & Beta & \\
\hline 1. ERC & .479 & .242 & .045 & .479 & .331 \\
\hline 2.ERC, ADFR & .533 & .167 & .052 & .314 & 3.237 \\
\hline $\begin{array}{c}\text { 3.ERC, ADFR, } \\
\text { INFSHA }\end{array}$ & .689 & .143 & .056 & .296 & \\
\hline $\begin{array}{c}\text { 4.ERC, ADFR, } \\
\text { INFSHA, CFED }\end{array}$ & .743 & .142 & .062 & .890 \\
\hline $\begin{array}{c}\text { 5.ERC, ADFR, } \\
\text { INFSHA, CFED, } \\
\text { ERP }\end{array}$ & .867 & .092 & .066 & & \\
\hline
\end{tabular}

\section{Conclusion}

This study examined the relationship between risk communication and review process and the entire risk management process in micro payment solutions. This was examined from the firms' or providers perspective. An empirical investigation was conducted into the understanding of the problem understand. Data was gathered from employees of micro payment providers in Ghana within a period of three (3) months. Furthermore, Pearson correlation and Linear regression analysis was conducted to test the hypothesis stated for this study. According to the statistical findings of this study it shown that firms information sharing and dissemination among both employees and client's aids in the mitigation of anticipated and unanticipated risks.

This study contributes to the body of literature on risk management especially in relation to micro or mobile phone payment. Furthermore, due to the limitation of this study further studies would be needed to confirm of risk communication and review in the long run continue to have a positive impact on risk management process in mobile 
payment system.

\section{Reference:}

[1].Campbell, D.T. (1995), The informant in quantitative research. American Journal of Sociology, Vol 60, 339-42.

[2].Anderson, M (1998), The electronic check architecture, financial service Technology consortium.

[3].Eduardo, H.D., Joao, P.A., Adraian, K.C., (2011), Mobile Money and payment: a literature review based on academic and practitioner-oriented publication (2001- 2011). Proceedings of SIG, GlobDer fourth Annual workshop, Shanghai, China.

[4].Marilyn, G., Miklos, V., (2002), Electronic Commerce: Security, Risk management and control, $2^{\text {nd }}$ edition: McGraw Hill

[5].Andersen, T.J (2006), Perspective on strategic risk management. Copenhagen, Denmark; Copenhagen Business School Press.

[6].Boholm, A. (2003), The cultural nature of risk: Can there be an anthropology of uncertainty?

[7].Reith, G. (2004), Uncertain times- the notion of 'risk' and the development of modernity, Time and Society.

[8].Bradbury, J.A., (1994), Risk communication in environmental restoration program. Kerzner, H. (2001), Project Management: a systems approach to planning, scheduling and controlling. $7^{\text {th }}$ edition. New York: Wiley.

[9].Neitlich, A. (2009), The importance of risk management for business owners. W.H.O, (1998), the application of risk communication to food standards and safety matters, A joint FAO/WHO expert consultation, Rome Italy.

[10]. Heilbun, K., Philipson, J, Breman, L \& Warren J,. (1996), Risk communication: clinicians report approach and perceived values. Paper presented at the annual convention of the American Psychological Association

[11]. Rowan, K.E.(1994), Why rules for risk communication are not enough: a problem- solving approach to risk communication

[12]. Thomas, S., Hruday, S.E. (1997), Risk of Death in Canada: What we know and how we know it. Edmonton: Alberta University Press www.rdec.gov.tw, 2006 